\title{
Possibility of Implementing Participatory Budgeting in the Kingdom of Bahrain
}

\author{
Maram Al Maskati ${ }^{1}$ \\ ${ }^{1}$ College of Business \& Finance, Department of Accounting, Ahlia University, Kingdom of Bahrain \\ Correspondence: College of Business \& Finance, Department of Accounting, Ahlia University, P. O. Box 10878, \\ Manama, Kingdom of Bahrain. Tel: 973-330-979-99. E-mail: contactmrm@gmail.com
}

Received: January 4, 2013

Accepted: January 31, 2013

Online Published: March 14, 2013

doi:10.5539/ijbm.v8n7p14

URL: http://dx.doi.org/10.5539/ijbm.v8n7p14

\begin{abstract}
This research aims at providing a general overview about participatory budgeting as well as providing a study on the possibility whether participatory budgeting can be implemented in the kingdom of Bahrain. The research was conducted with the assist of primary data as well as secondary data. The primary data consists of a survey distributed to 52 samples as well as an interview performed at the Ministry of Finance in the kingdom of Bahrain. The secondary data revolved around some previous studies as well as the assist of published books and the World Wide Web. The research analysis stated that people would love to see participatory budgeting being implemented in the kingdom. Finally, the author reached a conclusion stating that participatory budgeting can't be implemented in the kingdom at the mean time but it could be possible in the near future by starting the execution gradually in one of the five governorates in the kingdom with the assist of the Municipal Council which was appointed by the citizens. The author also suggested for participatory budgeting to be taught in schools as well as integrating an online tool to solve the problem of participation through the e-Government Authority.
\end{abstract}

Keywords: Bahrain, participatory budgeting, governmental accounting, strategic funding

\section{Introduction}

We always hear about annual budgets being distributed for this project or for that specific development plan, and we read in the newspapers about expenditures made and resources being allocated for the expansion of the national airport for instance, but we never get to have a say or give an opinion about where all the public money should be spent on.

Suppose that you live in a country where all the people of the community gather several times a year to perform meetings, where they can not only give their opinion about how the public budget should be spent but more generally take the lead on actually deciding how, where and on what the budget should be spent, and make critical decisions about their own budget, instead of being prepared behind the scenes only by specialists and experts, deciding how the public budget should be spent on behalf of the whole community without sharing their opinion.

This process is called Participatory Budgeting, where the citizens of one community calculate and negotiate the allocation of the public's resources and permits them to decide on which project the public's money should be spent.

By 2004 participatory budgeting has been implemented in more than 300 cities worldwide (Cabannes and Huber, 2004), and it's getting even more popular through the years. Numerous cities and countries are adopting the idea of participatory budgeting and are giving great reviews about it.

The main idea of this study is to explore the possibility whether participatory budgeting can be implemented in the Kingdom of Bahrain.

The study will try to provide an explanation to some questions:

- Is the Kingdom of Bahrain a suitable place and has the suitable environment to adopt participatory budgeting?

- Do we have the required conditions to implement it? 
- Will participatory budgeting succeed in Bahrain if it was implemented?

- This research paper will study the possibility whether participatory budgeting can be implemented in the Kingdom of Bahrain.

- This research aims:

- To identify participatory budgeting

- To explore the possibility of implementing participatory budgeting in the kingdom of Bahrain.

Research questions:

- What is participatory budgeting?

- Can participatory budgeting work in Bahrain?

At the end of this research paper, the conclusion will try to reach those objectives and answer the research questions asked.

\section{Literature Review and Previous Studies}

The study examines the town of Lawrence's experience with participatory budgeting. The town of Lawrence was one of the poorest towns in the U.S. and its community was made of Blacks, Latinos, and White people, with whites making only $1 / 3$ of the population (Baiocchi \& Lerner, 2007).

Baiocchi and Lerner aimed at the possibility whether participatory budgeting could work in the United States and compare it with the Canadian experiment, as well as the politics in the US presents various challenges and possibilities for participatory budgeting.

The authors concluded that participatory budgeting can be implemented in the US, and recommended that supporters of participatory budgeting should cooperate with other social movements fighting against inequality.

The elected representatives are supposed to represent the people and be their voice, since the people them selves elects them and put them in that position they can also choose to not re-elect them in the next cycle, thus unlike professional managers elected representatives are under pressure (Franklin, Ho \& Ebdon, 2009).

The authors aimed to explore how elected representatives distinguish the values of diverse participatory methods in addition to adding to present literature for there are very few surveys of this kind.

Franklin, Ho and Ebdon concluded by stating the importance of using participatory mechanisms in midsized cities and the relevant relationship between the citizens and the elected representatives.

In Guelph, Canada, people have started implementing participatory budgeting to allocate their city budget since 1999, and their first experience with participatory budgeting came after the Neighborhood Support Coalition (NSC) started to use participatory budgeting to allocate private and public funds, after the successful experience in Porto Alegre in Brazil (Pinnington, Lerner \& Schugurensky, 2009). The authors aimed to provide several lessons learnt through the Canadian experiment in Guelph in addition to presenting the conditions that helped this city in its development and it's caused challenges for its success. Despite the fact that participatory budgeting idea came from Latin America, Pinnington, Lerner \& Schugurensky explained the difference between the city of Guelph in Canada and Latin America where the latter tried the solve the limitation and weakness of the infrastructure. In Canada those services and needs are already met which leaves the residence with various motives to engage in participatory budgeting (Pinnington, Lerner \& Schugurensky, 2009). Participatory budgeting in Canada enhanced the support of government representatives, the councils support for the NSC and democratic participation as well as building a better democratic environment, and better government representatives and citizen's relationship, and just like the experience in the United States, it made other cities in Canada express an interest in participatory budgeting.

Zhang and Liao disagreed with some of the previous studies specifying the fact that some previous researches have been conducted stating that citizens participation requires two way dialogue between the citizens and the government. However, there hasn't been any study illustrating whether local governments will provide two way communications in the budget process (Zhang and Liao, 2011). In order to fill this academic shortage, Zhang and Liao took the initiative to conduct a study on whether local governments will provide this two way communication via a survey from municipal managers and mayors in New Jersey to study how public representatives' manner and awareness, type of government, council's variety and political affairs, and society characteristics influence the adoption of mechanisms of two-way communication for participatory budgeting.

The authors concluded and recommended the necessity of having two way communications for an effective 
citizen's participation and involvement in the budget process.

Another study by Haller and Faulkner aiming to enhance the efficiency of participatory budgeting. In Denver, Colorado where the first integration of the internet and technology in participatory budgeting programs occurred in March 2012 (Haller \& Faulkner, 2012).

Haller \& Faulkner aimed at demonstrating the differences between conducting participatory budgeting in a face to face communal way, and using the internet and online approaches to make it easier and flexible for citizens who are unable to attend meetings.

Participatory budgeting in the US is still in its early stages, and it will take time for it to reach the stage that Porto Alegre reached; however, participatory budgeting in Denver is in the head of those since it uses the internet approach to increase the publics' participation which is driving Denver to a brighter future (Haller \& Faulkner, 2012).

\subsection{The Difference between the Previous Studies and the Current Study}

After illustrating the previous studies, there are several differences to distinguish the previous studies from the current study. Some of these differences are:

The previous studies focused on the participatory budgeting experiences initiated in various cities, such as Porto Alegre, New Jersey, Guelph (Canada), while this study focuses on the possibility of applying participatory budgeting in the kingdom of Bahrain.

The first article conducted its study five years ago in 2007, while the fourth and fifth articles were made in 2009; article two and three were conducted in 2011 and early 2012 respectively. However, this article was accomplished in late 2012 .

While most of the previous studies used primary data as well as secondary data, this research was conducted using the primary data via a survey distributed and collected in the public sector as well as the private sector in addition to an interview conducted at the Ministry of Finance in the kingdom of Bahrain. Also, this article had the assist of some secondary data, using previous studies as well as books in the subject matter in addition to some of the World Wide Web resources.

\section{Research Methodology}

\subsection{Study Sample}

This section will reveal the study sample distributed and obtained in order to calculate the ratio of the study sample. This is relevant because it identifies the efficiency of the study conducted.

The questionnaire was distributed to 70 samples; 40 were distributed by hand to the public sector mostly (Ministries and governmental organizations), as well as the private sector, while 30 samples were distributed online to university students. The questionnaire was distributed to various occupations such as accountants, auditors, engineers, accounting students and marketers.

Out of the 70 samples distributed, 52 samples were obtained, which makes the study sample ratio equals to $74 \%$.

\subsection{Study Hypotheses}

This research consists of two hypotheses to test the prediction of this study, the study hypothesis is:

(Ha1): there is a possibility to implement participatory budgeting in Bahrain.

(Ho1): there is no possibility to implement participatory budgeting in Bahrain.

The first hypothesis will test whether the Kingdom of Bahrain has a chance to implement participatory budgeting, while the second hypothesis will test that participatory budgeting has no possibility of being implemented in the Kingdom.

\section{Discussion of Results}

The research analysis will split into two parts; the first part will demonstrate the descriptive analysis which will examine the first section of the survey and evaluate the general information, as well as the analyzing of the study questions. The second part will illustrate the testing of hypothesis. The research analysis will be conducted using SPSS. 


\subsection{Descriptive Statistics}

\subsubsection{General Information}

The following table will illustrate the data analysis of the general information.

Table 1. Personal details analysis

\begin{tabular}{|c|c|c|c|}
\hline Variables & & Frequency & Percentage $\%$ \\
\hline \multirow{3}{*}{ Gender } & Male & 21 & 40.4 \\
\hline & Female & 31 & 59.6 \\
\hline & Total & 52 & 100 \\
\hline \multirow{5}{*}{ Age } & Between 18 and 25 & 18 & 34.6 \\
\hline & Between 26 and 35 & 21 & 40.4 \\
\hline & Between 36 and 45 & 5 & 9.6 \\
\hline & More than 45 & 8 & 15.4 \\
\hline & Total & 52 & 100 \\
\hline \multirow{6}{*}{ Degree } & Undergraduate & 9 & 17.3 \\
\hline & Diploma & 1 & 1.9 \\
\hline & Bachelor & 29 & 55.8 \\
\hline & Master & 11 & 21.2 \\
\hline & $\mathrm{PhD}$ & 2 & 3.8 \\
\hline & Total & 52 & 100 \\
\hline \multirow{3}{*}{ Professional Certificate } & No & 48 & 92.3 \\
\hline & Yes & 4 & 7.7 \\
\hline & Total & 52 & 100 \\
\hline \multirow{3}{*}{ Nationality } & Bahraini & 49 & 94.2 \\
\hline & Other & 3 & 5.8 \\
\hline & Total & 52 & 100 \\
\hline
\end{tabular}

The data in table 1 shows us that the frequency of male responses was 21 , which makes the percentage equals $40.4 \%$. On the other hand, the frequency of female responses reached 31 which make the percentage equivalent to $59.6 \%$.

The data analysis shows us that the number of female respondents were more than the male respondents.

The results show us that there were no responses from the less than 18 category which makes both the frequency and percentage equals to zero. The frequency of people between the age 18 and 25 reached 18 , and the percentage was $34.6 \%$, while the age category between 26 and 35 had the most responses with a frequency of 21 and a percentage of $40.4 \%$.

Respondents between the age 36 and 45 had the least frequency which reached only 5 with a percentage equals to $9.6 \%$, while the age category more than 45 years old had a frequency of 8 and a percentage equals to $15.4 \%$ of respondents.

The frequency of people who have not graduated yet was 9 with a percentage of $17.3 \%$, on the other hand, the number of respondents who carry a Diploma was only 1 with a percentage equals to $1.9 \%$.

Respondents who carry a Bachelor degree had the highest frequency of 29 with a percentage up to $55.8 \%$, while those who carry a Masters degree reached 11 responses with a percentage equals to $21.2 \%$. The second least number of responses of people who carry $\mathrm{PhD}$ reached a frequency of only 2 with a percentage of $3.8 \%$. The frequency of people who don't carry any kind of professional certificate reached 48 which is the highest with a percentage equals to $92.3 \%$, while the number of people who carry a professional certificate reached only 4 and a percentage of $7.7 \%$.

The highest frequency of the nationality belonged to Bahrainis which reached 49 respondents and a percentage of $94.2 \%$, on the other hand, a frequency of only 3 from other nationalities responded to the survey, which makes the percentage equals to $5.8 \%$. 


\subsubsection{Study Information}

Table 2. The Kingdoms suitable environment

\begin{tabular}{|c|c|c|c|c|c|c|}
\hline & Variables & Frequency & Percentage \% & Mean & $\begin{array}{c}\text { General } \\
\text { Percentage \% }\end{array}$ & $\begin{array}{l}\text { Standard } \\
\text { deviation }\end{array}$ \\
\hline \multirow{6}{*}{$\begin{array}{l}\text { Q1. Kingdom of Bahrain has } \\
\text { the suitable environment to } \\
\text { implement participatory } \\
\text { budgeting. }\end{array}$} & Strongly disagree & 7 & 13.50 & 3.04 & $60.80 \%$ & 1.188 \\
\hline & Disagree & 9 & 17.30 & & & \\
\hline & Neither & 16 & 30.30 & & & \\
\hline & Agree & 15 & 28.80 & & & \\
\hline & Strongly agree & 5 & 9.60 & & & \\
\hline & Total & 52 & 100.00 & & & \\
\hline
\end{tabular}

The mean calculated was 3.04, which means in a scale out of 5 , most of the respondents almost agree that the Kingdom has the suitable environment to implement participatory budgeting, and the general percentage calculated for that agreement equal $60.8 \%$. The standard deviation was 1.188 , which determines that the frequency of responses varied among people.

In the researchers' opinion, the responses of people differed due to the current political situation in the Kingdom; some might believe that in order to implement participatory budgeting we must have a stable political environment, while others think that participatory budgeting is actually needed and would work efficiently in an environment such as in Bahrain.

Table 3. Government and citizens' relationship

\begin{tabular}{lrllllll}
\hline & & Variables & Frequency & Percentage $\%$ & Mean & General Percentage \% & Standard deviation \\
\hline Q2. Participatory budgeting & Strongly disagree & 1 & 1.90 & 4.33 & $86.60 \%$ & 0.879 \\
success mostly depends on & Disagree & 1 & 1.90 & & & \\
government and citizens trust & Neither & 5 & 9.60 & & & \\
relationship as well as & Agree & 18 & 34.60 & & & \\
supportive & political & Strongly agree & 27 & 51.90 & & & \\
environment. & & Total & 52 & 100.00 & & & \\
\hline
\end{tabular}

The Bahraini community is known to be highly educated; therefore, it could evaluate that participatory budgeting depends on trust along with suitable political environment.

Those who disagreed with the question probably have an opinion that since participatory budgeting could be executed at the command of not only the government but also other non governmental organizations, as it was explained in the questionnaire distributed, therefore people might not have to only deal with the government since it can be an individual social movement. But at the end, the final decision regarding the chosen projects goes back to the government.

Table 4. Continuous meetings throughout the year

\begin{tabular}{|c|c|c|c|c|c|c|}
\hline & Variables & Frequency & Percentage \% & Mean & General Percentage \% & $\begin{array}{l}\text { Standard } \\
\text { deviation }\end{array}$ \\
\hline Q3. I am able and willing & Strongly disagree & 6 & 11.50 & 3.69 & $73.80 \%$ & 1.351 \\
\hline to attend continuous & Disagree & 5 & 9.60 & & & \\
\hline meetings through out the & Neither & 6 & 11.50 & & & \\
\hline year to have a decision in & Agree & 17 & 32.70 & & & \\
\hline $\begin{array}{l}\text { my city's public budget if } \\
\text { participatory budgeting }\end{array}$ & Strongly agree & 18 & 34.60 & & & \\
\hline $\begin{array}{l}\text { was implemented in } \\
\text { Bahrain. }\end{array}$ & Total & 52 & 100.00 & & & \\
\hline
\end{tabular}

The results shown in table 4 can make us determine how the Bahraini community is willing to make changes, as it turns out that the idea of participatory budgeting was favored by the Bahraini community. People realize that 
the idea of participatory budgeting could be beneficial for everyone; therefore they are willing to try it despite their cluelessness about the unknown results. Those who disagreed might know that they can't be committed to continuous meetings, besides the fact that some are willing but are unable to attend due to some other personal or work commitments.

Table 5. Affect on fraud and better decision making

\begin{tabular}{lllllll}
\hline & Variables & Frequency & Percentage \% & Mean & General Percentage \% & Standard deviation \\
\hline Q4. Participatory budgeting can & Strongly disagree & 3 & 5.80 & 3.94 & $78.80 \%$ & 1.11 \\
reduce fraud rates and lead to & Disagree & 2 & 3.80 & & & \\
better decision making. & Neither & 9 & 17.30 & & & \\
& Agree & 19 & 36.50 & & & \\
& Strongly agree & 19 & 36.50 & & & \\
& Total & 52 & 100.00 & & & \\
\hline
\end{tabular}

People realize that participatory budgeting will deal mostly with the public, and all the financial information will be within reach; therefore, the process of stating the public budget will be known and shown to everyone, so there will be no chance for manipulation or fraud which explains the results of high agreement in table 5. Also, people might think it could lead to efficient decisions since the decisions will be in their hands for the one who wears the shoe can tell best where it hassles. Politicians might then stop taking control over everything and therefore the community will accomplish better decision making.

Table 6. The adoption of participatory budgeting

\begin{tabular}{lllllll}
\hline & Variables & Frequency & Percentage $\%$ & Mean & General Percentage \% & Standard deviation \\
\hline Q5. If all the required conditions & Strongly disagree & 8 & 15.40 & 2.92 & $58.40 \%$ & 1.218 \\
were available in Bahrain, & Disagree & 11 & 21.20 & & & \\
Bahrain government will adopt & Neither & 15 & 28.80 & & & \\
participatory budgeting strategy. & Agree & 13 & 25.00 & & & \\
& Strongly agree & 5 & 9.60 & & & \\
& Total & 52 & 100.00 & & & \\
\hline
\end{tabular}

According to the results, we can conclude that the community isn't able to predict the governments' moves; people can't make a choice whether the government will adopt participatory budgeting or at least consider it, and that could be because the Bahraini community might in fact need participatory budgeting but the government and the society as well realize that they are not ready for it just yet. It could be difficult for the government to shift to an entirely new budgeting strategy after it has implemented a certain strategy for years.

Table 7. The openness of the Bahraini community

\begin{tabular}{lllllll}
\hline & Variables & Frequency & Percentage $\%$ & Mean & General Percentage \% & Standard deviation \\
\hline Q6. I think the Bahraini & Strongly disagree & 4 & 7.70 & 3.37 & $67.40 \%$ & 1.205 \\
community is open to changes & Disagree & 11 & 21.20 & & & \\
like participatory budgeting. & Neither & 7 & 13.50 & & & \\
& Agree & 22 & 42.30 & & & \\
& Strongly agree & 8 & 15.40 & & & \\
& Total & 52 & 100.00 & & & \\
\hline
\end{tabular}

In the researchers' opinion, the Bahraini community is in fact open to changes, but since we have a variation in responses, the disagreement opinions could be due to the cultural environment in the Kingdom of Bahrain that people are anxious about new changes. Despite the fact that the Bahraini community is highly educated, there are still some Bahraini individuals who are known of being traditional and conservative and might not accept the idea of attending such meetings and debates throughout the year. 
Table 8. Chances for more democratic decisions

\begin{tabular}{lllllll}
\hline & Variables & Frequency & Percentage $\%$ & Mean & General Percentage \% & Standard deviation \\
\hline Q7. Participatory budgeting can & Strongly disagree & 1 & 1.90 & 3.96 & $79.20 \%$ & 0.969 \\
be a good opportunity for the & Disagree & 4 & 7.70 & & & \\
community to make more & Neither & 7 & 13.50 & & & \\
democratic decisions. & Agree & 24 & 46.20 & & & \\
& Strongly agree & 16 & 30.80 & & & \\
& Total & 52 & 100.00 & & & \\
\hline
\end{tabular}

As previously mentioned, the Bahraini community acknowledges the fact that participatory budgeting will function by them mostly, since decision making will be in their hands (despite the fact that the final decision goes to the government); participatory budgeting can actually lead to more democratic decisions since democracy is one of participatory budgeting's' best qualities and advantages.

Table 9. Availability of financial information

\begin{tabular}{lllllll}
\hline & Variables & Frequency & Percentage $\%$ & Mean & General Percentage \% & Standard deviation \\
\hline Q8. The necessary information & Strongly disagree & 8 & 15.40 & 2.87 & $57.40 \%$ & 1.237 \\
of the financial situation and so & Disagree & 13 & 25.00 & & & \\
are available to the Bahraini & Neither & 15 & 28.80 & & & \\
citizens in order to be able to & Agree & 10 & 19.20 & & & \\
participate in participatory & Strongly agree & 6 & 11.50 & & \\
budgeting. & Total & 52 & 100.00 & & & \\
\hline
\end{tabular}

According to the results, we can determine that most of the respondents are unaware whether the financial information are available or not, since most of the answers were neutral. Those who disagreed with the question might believe that the information within reach isn't sufficient for the community to conduct participatory budgeting.

Table 10. The knowledge of the Bahraini community

\begin{tabular}{lllllll}
\hline & Variables & Frequency & Percentage $\%$ & Mean & General Percentage \% & Standard deviation \\
\hline Q9. The Bahraini community is & Strongly disagree & 5 & 9.60 & 3.48 & $69.60 \%$ & 1.213 \\
knowledgeable and educated & Disagree & 7 & 13.50 & & & \\
enough to adapt to participatory & Neither & 7 & 13.50 & & & \\
budgeting easily. & Agree & 24 & 46.20 & & & \\
& Strongly agree & 9 & 17.30 & & & \\
& Total & 52 & 100.00 & & & \\
\hline
\end{tabular}

In the researchers' opinion, the agreed responses are due to the fact that the Bahraini community is actually highly educated. More than half the respondents carried Bachelor degrees as well as Masters and PhD's among other professional certificates. Also, the English language is considered the second language in the Kingdom, and others use it as a first language; hence, the Bahraini community might not have a problem adapting to participatory budgeting or actually practicing it.

However, in spite of the fact that English is considered the second language, some Bahraini individuals still lack the ability to speak proper English and find it very difficult to communicate with, which could explain the disagreement in opinions. 
Table 11. The awareness of Bahrain's general budget

\begin{tabular}{lllllll}
\hline & Variables & Frequency & Percentage $\%$ & Mean & General Percentage \% & Standard deviation \\
\hline Q10. I am aware of how the & Strongly disagree & 8 & 15.40 & 2.81 & $56.20 \%$ & 1.138 \\
Bahraini government states the & Disagree & 13 & 25.00 & & & \\
general budget and the steps it & Neither & 14 & 26.90 & & & \\
takes. & Agree & 15 & 28.80 & & & \\
& Strongly agree & 2 & 3.80 & & & \\
& Total & 52 & 100.00 & & & \\
\hline
\end{tabular}

The previous result could be because despite the fact that the citizens are not involved in preparing the general budget, most of the responses verified that they are aware of the budgetary system and allocation due to the involvement of the parliament which represents the Bahraini community. Those who agreed could have an interest in following the latest news about the parliament involvement.

However, the testing results indicate that responses lean more on being unaware to neutral about how the government states the general budget, hence we can determine that the Bahraini community got used to having the general budget being prepared by the government without any direct involvement from the citizens, therefore they show no interest in learning about the budget strategy followed.

Table 12. The fairness of the budget allocation in Bahrain

\begin{tabular}{lllllll}
\hline & Variables & Frequency & Percentage $\%$ & Mean & General Percentage \% & Standard deviation \\
\hline Q11. The budgetary system and & Strongly disagree & 7 & 13.50 & 2.75 & $55.00 \%$ & 1.1 \\
budget allocation are fairly & Disagree & 15 & 28.80 & & & \\
reasonable in Bahrain. & Neither & 17 & 32.70 & & & \\
& Agree & 10 & 19.20 & & & \\
& Strongly agree & 3 & 5.80 & & & \\
& Total & 52 & 100.00 & & & \\
\hline
\end{tabular}

Given the previous results, we can determine that the majority of the respondents are unaware of the budgetary system and budget allocation to make a decision whether it's fair or not.

As previously mentioned, a significant amount of people show no knowledge of how the publics resources are being allocated, possibly because of other work commitments that keep them preoccupied to learn about this point.

However, there are still a fine number of people who are actually aware of how the government states the budget and the strategy it follows and believe that it's being executed fairly, probably due to their close work field in that matter or they could be just satisfied with what they get.

Table 13. The acceptance of participatory budgeting in Bahrain

\begin{tabular}{llllllll}
\hline & & Variables & Frequency & Percentage $\%$ & Mean & General Percentage \% & Standard deviation \\
\hline Q12. I would love to see & Strongly disagree & 0 & 0.00 & 4.23 & $84.60 \%$ & 0.807 \\
participatory budgeting being & Disagree & 2 & 3.80 & & & \\
implemented in Bahrain. & Neither & 6 & 11.50 & & & \\
& & Agree & 22 & 42.30 & & & \\
& Strongly agree & 22 & 42.30 & & & \\
& Total & 52 & 100.00 & & & \\
\hline
\end{tabular}

The significantly high mean of 4.23, indicates that the majority of the responses had an agree opinion as well as strongly agree. The standard deviation (0.807) demonstrates that the responses didn't vary in the frequency distribution.

In the researchers' opinion, the Bahraini community would love to see a change occurring, and would love to be a part of that change which explains the weak disagreement. 
Table 14. The success of participatory budgeting in Bahrain

\begin{tabular}{lllllll}
\hline & Variables & Frequency & Percentage \% & Mean & General Percentage \% & Standard deviation \\
\hline Q13. It would be a successful & Strongly disagree & 2 & 3.80 & 3.73 & $74.60 \%$ & 0.952 \\
experiment if participatory & Disagree & 1 & 1.90 & & & \\
budgeting was implemented in & Neither & 17 & 32.70 & & & \\
Bahrain. & Agree & 21 & 40.40 & & & \\
& Strongly agree & 11 & 21.20 & & & \\
& Total & 52 & 100.00 & & & \\
\hline
\end{tabular}

The Bahraini community appears to be interested in the idea of participatory budgeting and have high expectations for it. The Bahraini community believes that a strategy such as participatory budgeting is needed in the area in order to enhance democracy, citizens' participation in the public resources allocation in addition to boost the education level in Bahrain.

However, the disagreements could be possibly because people believe that participatory budgeting is not what they need at the mean time, or could simply be lack of knowledge.

\subsection{Testing of Hypotheses}

Table 15. One sample T-test

\begin{tabular}{llll}
\hline Question & Mean & T.test & Sig \\
\hline Q1. Kingdom of Bahrain has the suitable environment to implement participatory budgeting. & 3.04 & 0.234 & 0.816 \\
Q2. Participatory budgeting success mostly depends on government and citizens trust relationship as well as & 4.33 & 10.881 & 0.000 \\
supportive political environment. & & \\
Q3. I am able and willing to attend continuous meetings through out the year to have a decision in my city's & 3.69 & 3.695 & 0.001 \\
public budget if participatory budgeting was implemented in Bahrain. & 3.94 & 6.122 & 0.000 \\
Q4. Participatory budgeting can reduce fraud rates and lead to better decision making. & -0.455 & 0.651 \\
Q5. If all the required conditions were available in Bahrain, Bahrain government will adopt participatory & 2.92 & \\
budgeting strategy. & 3.37 & 2.187 & 0.033 \\
Q6. I think the Bahraini community is open to changes like participatory budgeting. & 3.96 & 7.153 & 0.000 \\
Q7. Participatory budgeting can be a good opportunity for the community to make more democratic decisions. & -0.785 & 0.436 \\
Q8. The necessary information of the financial situation and so are available to the Bahraini citizens in order to & 2.87 & & \\
be able to participate in participatory budgeting. & 3.48 & 2.589 & 0.006 \\
Q9. The Bahraini community is knowledgeable and educated enough to adapt to participatory budgeting easily. & 2.81 & -1.218 & 0.229 \\
Q10. I am aware of how the Bahraini government states the general budget and the steps it takes. & 2.75 & -1.638 & 0.108 \\
Q11. The budgetary system and budget allocation are fairly reasonable in Bahrain. & 4.23 & 10.995 & 0.000 \\
Q12. I would love to see participatory budgeting being implemented in Bahrain. & 3.73 & 5.535 & 0.000 \\
Q13. It would be a successful experiment if participatory budgeting was implemented in Bahrain. &
\end{tabular}

The first question got a T.test result of 0.234 and a Sig equal to 0.816 ; those results indicate that major responses leaned more to disagree with the question, which means that most of the respondents have a neutral to a disagreeing opinion that the kingdom of Bahrain has the suitable environment to implement participatory budgeting.

The second question had a result of 10.881 T.test and a Sig of 0.000 ; the results demonstrated indicate that the major responses agreed with the question, which means that the respondents believe that participatory budget success mostly depends on the trust between the citizens and the government relationships as well as supportive political environment.

The third question had a T. test equal to 3.695 and a Sig of 0.001 indicating that the major responses agreed with the question. Nearly all the respondents agreed on their ability and willingness to attend continuous meetings throughout the year in order to participate in preparing the general budget and have an opinion if participatory budgeting was implemented in the kingdom.

The forth question had a T. test equals to 6.122 and Sig of 0.000 . The results signify that the majority of the responses agreed with the stated question. Almost all the respondents agreed that participatory budgeting can reduce fraud rates and lead to better decision making. 
Question fives' results were as following: the T. test was calculated to be -0.455 , and the Sig was 0.651 . The results indicate that the most responses disagreed with the question, since the T. test was negative and the Sig was more that 0.05 . The majority of the respondents had a disagreeing opinion that if all the required conditions were available in the Kingdom; the government of Bahrain will adopt participatory budgeting strategy.

Question six had the following results: the T. test was calculated to be 2.187 and the Sig was 0.033 . The previous results show that the majority of the responses agreed with the question, which means that most of the respondents agree that the Bahraini community is an open community to major changes such as participatory budgeting.

The seventh question had a calculated T. test of 7.153 and a Sig equal to 0.000 which indicates that the majority of the responses agree with the stated question. Most of the respondents agreed that participatory budgeting can be a good opportunity to make more democratic decisions where they can have an opinion on the general budget and even make decisions on where the given resources should be allocated.

Question eight got a T. test of -0.785 and a Sig equal to 0.436 . The results indicate that the majority of the responses disagreed with the question. Since the T. test was negative and the Sig was more than 0.05 which means that most of the respondents disagreed that the necessary information of the financial situation are available to the Bahraini citizens to be able to participate in participatory budgeting.

The ninth question results were the following: the T. test calculated was 2.859 and the Sig was equal to 0.006 . The demonstrated results indicate that the greater part of the responses agreed with the question indicating that the Bahraini community is knowledgeable and educated enough to adapt easily to participatory budgeting.

The tenth question results were as follows: the T. test calculated was equivalent to -1.218 and a Sig of 0.229 which indicates the disagreement responses for the greater part since the T. test was negative and the Sig was more than 0.05 . The results show us how most respondents denied their awareness of how the government of Bahrain states the general budget and the budget system and strategy it follows.

Question eleven had a negative T. test result equivalent to -1.638 , and a Sig greater than 0.05 which is equal to 0.108 . The previous results indicate that the majority of the responses leaned more to disagreeing with the question, which means that the respondents had an opinion that the budgetary system and budget allocation are not fairly reasonable in the kingdom of Bahrain.

Question twelve had the following results: the T. test calculated was equal to 10.995 and the Sig was 0.000 . the results show us that most of the responses agreed with the question which means that the majority would love to see participatory budgeting being implemented in the kingdom of Bahrain.

Finally, the last questions' results were as follows: the T. test calculated was equal to 5.535 and the Sig was 0.000 which tells us that the greater part of the responses agreed with the question. Most of the respondents agreed that participatory budgeting would be a successful experiment if it was implemented in the kingdom of Bahrain.

\subsection{Possibility of Implementation in the Kingdom of Bahrain}

\subsubsection{Bahrain's' Budgetary System}

Bahrain is a small island with an estimated population of more than 1 million Bahraini citizens in 2011. In 2002, it was announced by his Majesty the king of Bahrain, king Hamad bin Isa Al Khalifa, that the Kingdom will be divided into five governorates; Capital governorate, Central governorate, Muharraq governorate, Northern governorate and Southern governorate, and each had its own governor who in turn is elected by the citizens every four years.

Bahrain's budgetary system according to the general budget act of the kingdom is settled by the Ministry of Finance, and the execution of the budget allocation remains with the director of the budget department.

Recently the kingdom of Bahrain has adopted a new approach for preparing the general budget of $2011-2012$. This new approach is called Strategic Funding, which is a way for preparing the budget that depends on making a connection between the strategic objectives and the priorities with the financial funds. This approach specifies the objectives of the strategy to observe the execution of the budget throughout the budget cycle.

Strategic funding is considered one of the major initiatives in the National Economic Strategy (NES) developed by the Kingdom of Bahrain and which sets goals of six years to be accomplished by 2014. Strategic funding is based on connecting the strategic objectives with the available financial resources and is one of the basic priorities in the public sector; also it's considered the main tool to observe and monitor the budget performance and achieve efficiency in the government, in addition to the efficient use of resources in the public sector. 
Strategic funding is implemented in preparing the publics' budget and plays a primer role in achieving the goals stated within the NES and enhance the governments' transparency to attain one of the Economic Visions principals of the Kingdom for 2030 which was established in 2008 by his Majesty the King.

Strategic funding also enhances the procedure of decision making. The main advantages of strategic funding budgeting method are:

It allows the distribution of funds according to priorities; it enhances the accountability, clearness and simplicity of the distribution of funds; it provides a better control and management over expenditures which in turn enhance the efficiency and effectiveness of the budget and finally, Ministries and governmental organizations focus on the objectives and projects set.

According to the Head of Budget Coordination at the Ministry of Finance (Note 1); the only difficulty facing the strategic funding is making arrangements on the recurrent expenditures since it contains frequent figures.

It's essential to know that the Bahraini economy is mixed. The oil and natural gas are classified as the only major natural resources that rule and control the economy in Bahrain despite the governments' efforts to vary (Ramadhan, 2009).

Before starting the budget preparations; a committee is formed and appointed by the Minister of Finance; this committee includes the executive of financial affairs; senior budget analyzer, the department chief and the accountant. The budget committee is directed by either the financial affairs executive or the director of the financial resources.

The first step in preparing the general budget is to determine the estimation of income and revenues which are allocated to cover some general expenses; the Ministry of Finance with the collaboration of the other Ministries and governmental organizations start the initial estimates of revenue according to the Minister of Finance instructions and rules on the determined date, and any delay from any certain direction, the Ministry of Finance will take the initiative to estimate the revenues on its own after informing that Ministry. The Ministry takes into consideration any unplanned changes that might occur.

After that, the Ministry of Finance prepares the final estimates of the income and revenues.

The revenues section is categorized by the sort of revenues; they consist of oil revenues and non-oil revenues, as well as grants.

The next step is for the other Ministries to estimate the expenses taking into account the estimated revenues, and then provide them to the Ministry of Finance (director of budget), including notes on the necessary information and explanation to justify each estimated figure in the budget.

After that, the director of budget in the Ministry of Finance will discusses the budget and reviews it with the budget committee elected by the director. Sometimes the elected committee may represent other Ministries. The Ministry will search the expenditures estimates of the other Ministries, taking into consideration the expenditures estimated for the work force and the other Ministries to discuss the size of these estimates and their needs.

The Ministry of Finance afterward starts preparing the budget document according to rules and regulations; it also prepares a statement on the financial and economic situation of the kingdom and the measures taken to implement the budget as well as the influence on the new budget.

The document should include:

- $\quad$ Prediction of the revenues and grants.

- Prediction of frequent project expenses.

- Prediction of interest and settlement of loans;

- Prediction of the budget shortage along with the suggested ways to fund it.

- The revenues and expenditures of the prior year.

- The revenues and expenditures of the year before the previous year.

After that, the Minister of Finance will submit the adoption of the budget to the council of Ministers for approval in order to be presented to the parliament before the end of the current financial year by at least two months to discuss it and then allocate it to the Shura Council.

The role of the parliament revolves only around discussing the general budget; however, the representatives' can't make any changes on it, not without the government approval, and if the budget wasn't approved by the 
parliament, the budget could be reduced.

According to the general budget act, a Royal Decree draft must be prepared and submitted by the director of budget to be approved and signed by his Majesty King Hamad Bin Isa Al Khalifa (Ramadhan, 2009).

Finally, the general budget is implemented, and all the Ministries and other governmental bodies are informed to start executing it.

Ministries may not exceed their expenses or expenditures on a certain project, unless approved by the law, also, the ministers and heads of governmental organizations are obligated to provide the Council of ministers with the audited financial accounts along with the detailed results reached compared with the stated objectives of the project, within three months after the end of the fiscal year. A copy of those documents is presented to the Minister of Finance afterwards.

The kingdom of Bahrain might not involve the citizens directly in participating in setting the general budget, but there have been some regular visits by the royal family, the King and the Prime Minister, to the governorates in the kingdom where they meet the citizens directly and ask them about their demands and needs and report them to the specialized ministry or governmental organization where they get prioritized and translated into numbers.

It's not difficult or impossible to implement participatory budgeting in Bahrain, the community of Bahrain showed a high interest in the process. An interview made with the Head of Budget Coordination at the Ministry of Finance was able to answer some critical questions and provide some interesting recommendations.

So what would be the benefits of participatory budgeting if it was implemented in the kingdom? And what are the obstacles facing the implementation of participatory budgeting in Bahrain?

Participatory budgeting could be a great opportunity for the Bahraini community to communicate with each other and learn about each others needs and demands; also it's a superior chance for them to gain knowledge and information about the actual financial situation of the kingdom which will help them make better decisions. Participatory budgeting could be a good indicator of how much the community is educated and knowledgeable; suppose that participatory budgeting was in fact implemented in Bahrain, people's decisions regarding the favorable projects will show whether they are actually thinking about their individual selves or the place and the district they are living in.

The former point could be considered an obstacle when it comes to implementing participatory budgeting in the kingdom, people's choices of projects could reflect their own interest instead of the majorities. Also, if for example BD1 million was allocated for a certain district and projects were prioritized, the next year, people might ask for more and claim that BD1 million was not sufficient as people's demands will keep growing with time.

Another disadvantage is that the Bahraini community might not be committed to continuous meetings and debates throughout the year. The cultural environment plays a critical role as well; although the Bahraini community might seem open and outgoing but if there will be any participation; it will be limited to a certain category, such as a certain age and a certain occupation for there are many conservative families and individuals who can't accept the idea of such meetings.

Since participatory budgeting takes time for it to actually have an effect, people in Bahrain might be disappointed and lose faith easily because when they start the participatory budget strategy, higher expectations will be set.

Regardless of the limitations and obstacles, participatory budgeting still remains a good idea to be implemented gradually and partially in the kingdom of Bahrain where the citizens' voices could be heard.

\section{Discussion of Conclusion and Recommendations}

While a high percentage of responses tended to neither agree nor disagree agree that the kingdom of Bahrain has the suitable environment to implement participatory budgeting; a very high percentage of respondents stated that they would love to see it being implemented in Bahrain.

Many respondents also agreed that participatory budget can lead to better decision making since the people will decide what they want by themselves. The results also showed the willingness of the majority to participate in meetings and debates throughout the year, which gives a good indicator of how the Bahraini community is willing to make changes.

At the end, we conclude this study based on the survey, interview and research conducted; the results indicate that there is possibility for participatory budgeting to be implemented in the kingdom, and in spite of the 
previous opinions, it was agreed in the interview at the Ministry of Finance that a strategy such as participatory budgeting is in fact needed in the kingdom, for everyone want their voices to be heard.

However, participatory budgeting may not be fully and precisely implemented at the mean time, but there is a possibility in the near future, since the kingdom is divided into six governorates, the process could be experienced in one governorate with the help of the Municipal Council and the elected representative of that governorate, by directly communicating with the citizens and providing them with specific amount of money to be allocated by them, and then report those prioritized needs by the representatives to the Council of Ministers to discuss those demands. Results then could be illustrated then along with the difficulties faced and the suggested effort to overcome them, and finally judge the process and whether it could be continued.

It's true that it's a long process in order for participatory budgeting to have an effect, especially in a country such as Bahrain, but it's not impossible to implement it even if it lacks the conditions and suitable environment now, the near future might hold the opportunity for participatory budgeting to be executed, although in the researchers' opinion, every country or district can make their own rules and conditions based on their special circumstances.

The author would like to draw the attention to the limitations of the study stating that the theories and conclusion reached are limited to this study exclusively, since the survey was distributed to only 52 different entities due to the lack of time.

The recommendation suggested in this study is to overcome the limitations and obstacles faced by the kingdom of Bahrain such as solving the problem of participation by integrating an online approach for those who can't participate directly taking advantage of the e-Government Authority. Also it might be difficult for the community to elect a representative among them, so the problem could be solved by involving the Municipal Council which was already elected by the citizens.

It could also be a good idea to start teaching participatory budget in schools as a preparation for the coming generation to gain knowledge about the main idea as well as knowledge about the kingdoms' financial situation and budgetary system. Conducting a study to test the potential effectiveness and efficiency of participatory budgeting on the kingdom before adopting it, is also a relevant point.

Finally, proceed the current study by having a real life experience and bring participatory budgeting to life in one governorate in the kingdom and record the actual results is also one of the suggested future studies.

\section{Acknowledgement}

I would like to take the opportunity to thank my advisor Dr. Allam Hamdan for his guides and opening the door to great future opportunities.

I would also like to express my gratitude to all those who contributed directly and indirectly in this project. First of all my family; my father for his continuous support and patience to drive me around; my mother for her non stop prayers, my sister Masiam for her eagerness to listen; my brothers, Mzaen for his constant encouragement and valuable advices; Mustafa for his motivating sense of humor and Issa for his willingness to help; and also to my friend Fatima and all my other friends and family and everyone who took the time to fill in the questionnaire. I would also like to thank Mr. Nabeel Al Doy for his great and highly appreciated help; Mr. Najeh Al Tawash for giving me the time to interview him and his willingness to help; Mrs. Layla Al Suwaidy for her valuable information, and everyone at the Ministry of Finance who helped and supported my research; and finally to all those who lent a hand, supported and believed in me throughout this research, I give my most thanks.

\section{References}

Baiocchi, B., \& Lerner, J. (2007). Could Participatory Budgeting Work in the United States?

Budget Law Booklet. (2010). Retrieved from http://www.mof.gov.bh/showdatafile.asp?rid=2157\&ftype=file1

Cabannes, Y., \& Huber, R. (2004). 72 Frequently asked questions about participatory budgeting. Nairobi: UN-HABITAT. Retrieved from http://www.unhabitat.org/documents/faqqPP.pdf

Franklin, A. L., HO, A. T., \& Ebdon, C. (2009). Participatory Budgeting in Midwestern States: Democratic Connection or Citizen Disconnection? Public Financial Publications, 29(3), 52-73.

Haller, C., \& Faulkner, G. (2012). Participatory Budgeting in Denver, Colorado. National Civic Review, 101(3), 23-25. http://dx.doi.org/10.1002/ncr.21083

Lerner, J. (2011). Participatory Budgeting: Building Community Agreement Around Tough Budget Decisions.

New Budget Process. (2011). Retrieved from http://www.mof.gov.bh/topiclist.asp?ctype=budget\&id=870 
Pinnington, E., Lerner, J., \& Schugurensky, D. (2009). Participatory budgeting in North America: The case of Guelph. Canada.

Ramadhan, S. (2009). Budgetary accounting and reporting practices in Bahraini governmental units: An empirical study. International Business Review, 168-183. http://dx.doi.org/10.1016/j.ibusrev.2009.01.001

Strategic Funding. (2011). Retrieved from http://www.mof.gov.bh/topiclist.asp?ctype=budget\&id=871

Wampler, B. (2000). A Guide to Participatory Budgeting. Retrieved from http://www.internationalbudget.org/wp-content/uploads/A-Guide-to-Participatory-Budgets.pdf

Zhang, Y. H., \& Liao, H. (2011). Participatory Budgeting in Local Government: Evidence from New Jersey Municipalities. Public Performance \& Management Review, 35(2), 281-302. http://dx.doi.org/10.2753/PMR1530-9576350203

\section{Note}

Note 1. Head of Budget Coordination at the Ministry of Finance: Mr. Najeh Al Tawash. 